\title{
The Underrepresentation of Women in Moroccan Drama Movies: Through the Lens of Moroccan Male Filmmakers
}

\author{
Sarra Chahbane \\ Doctoral Student in Media, Gender, and Cultural Studies Sidi Mohamed Ben Abdellah University, Morocco
}

\begin{abstract}
This article strives to illuminate the interlinked relationship between movies, gender, and culture in the Moroccan context. More specifically, it aims at exploring the way women are misrepresented and misinterpreted in Moroccan drama movies, and particularly through the lens of Moroccan male filmmakers. For this specific reason, two Moroccan movies are selected, critically analyzed, and thoughtfully compared using qualitative content analysis. The first one is $O k b a L i k$, a comedy-drama movie directed by Yassine Fennane and released in 2010. The second one is Hayat, a road trip drama movie directed by Raouf Sebbahi and released in 2017. Although the two movies are seven years apart, results have revealed that the culture of domineering men and subservient women is still prevalent in Moroccan drama movies. Both male filmmakers reinforce and perpetuate patriarchal ideology through the depiction of different forms of male domination and female subordination. Results have also shown that both movies make a significant contribution to the misrepresentation, dehumanization, objectification, and sexualization of Moroccan women.
\end{abstract}

KEYWORDS: Moroccan drama movies, male filmmakers, gender stereotypes, patriarchy, male domination, female subordination

\section{INTRODUCTION}

Over the centuries, the mass media have played a leading role in defining, portraying, and constructing social reality. It has significantly blurred boundaries, producing a mass society and creating an interconnected global village, where all cultures have been squeezed into one global culture. This global cultural interconnectedness has been constructed to control the human mind to act and react based on what the media represent.

The term "representation" in media studies demonstrates the way gender, national identity, age, religion, ethnicity, and other social factors are portrayed in the media to heavily influence what we think, how we think, and why we think about certain topics and not others. Media representation is a process of constructing meaning through filtering people's vision of reality (Talbot, 2007, p.16). This term had been carefully tackled by Stuart Hall in his most recognized book Representation: Cultural Representations and Signifying Practices (1997). In his book, Stuart Hall simply defined representation as "the production of meaning through language" (p.16). By language, Hall does not only refer to grammatical rules and the way words are arranged but more importantly to symbols, signs, codes, and the latent meanings of every media text. The focus of Hall has been mainly on visual representations (Hagey \& MacKay, 1994, p.108), as they are considered the most prevalent, appealing, and engaging form of media that paves the way for unlimited interpretations (Gorton, 2009, p.27) where addressees may either act as passive consumers or active participants.

Significantly, the term "underrepresentation" was first coined by George Gerbner in his sociological theory "symbolic annihilation" which was proposed in 1976. Gerbner used the term to describe the absence and the misrepresentation of some groups in the media. The term was then developed by Gaye Tuchman and her colleagues in 1978 who employed it to particularly address gender stereotypes in visual media. Tuchman et al. tackled the way women are either absent or misrepresented on TV. In their book, Hearth and Home: Images of Women in the Mass Media, Tuchman et al. discussed the way television acts as people's common culture. Television has brought people together from all around the world to perceive media texts the way it is intended to, accept them as they are without any critical responsiveness, and act based on them. In the same book, Tuchman et al. described television as "the new religion" (p.47) and they particularly referred to "the preindustrial notion of religion" (p.47) where one feels that they are indoctrinated into specific religious beliefs without having enough information, knowledge, and answers about that religion. When watching television, people give their consent both intentionally and unintentionally to the stereotypical assumptions that are constructed about women (Shrum, Burroughs, and Rindfleisch, 2005, p. 475). The more individuals watch televised content that promotes gender inequality, the more acceptable and normalized these stereotypes will become.

As far as gender stereotypes in movies are concerned, Laura Mulvey explored in her essay on Visual Pleasure and Narrative Cinema (1975) the way gender shapes the distribution of power in the cinema industry. In her essay, Mulvey developed a feminist 


\section{International Journal of Current Science Research and Review}

ISSN: 2581-8341

Volume 04 Issue 01 January 2021

DOI: 10.47191/ijcsrr/V4-i1-07, Impact Factor: 6.825

IJCSRR@ 2021

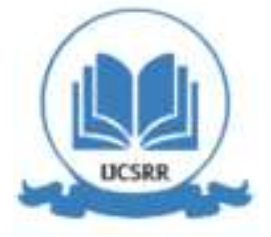

www.ijcsrr.org

theory called the male gaze which suggests that women are perceived from the lens of a heterosexual man and that they are represented from an objectified, sexualized, and victimized point of view. In her essay, Laura Mulvey elucidated the way patriarchal society's perception of gender roles is mirrored in films, describing the way men and women receive unequal attention and are linked with highly stereotyped images. In the same essay, Mulvey employs a thought-provoking statement that needs to be scrutinized: "Woman as Image, Man as Bearer of the Look" (p.62). The male gaze theory theorizes that men always belong to the dominant group whose responsibility lies in setting rules and guidelines, even when it comes to who has the right to look and who should only be looked at. They are the ones who make decisions and distribute roles. In simply formulated words, men own the power to look and act at the same time (Manlove, 2007, p.89). In contrast, women play a weaker role; they are placed in a certain scene to be looked at and acted upon. Women are therefore deprived of their cognition, agency, and freedom, and are reduced to a body and an image.

This research aims at examining the position of women in Moroccan movies. More particularly, the ultimate objective of this paper is to illustrate the extent to which women are underrepresented by Moroccan male filmmakers. To achieve this objective, two popular and controversial Moroccan drama movies will be carefully analyzed using qualitative content analysis. The first one is $O k b a$ Lik (a common Moroccan cultural expression used in this context to indicate someone's wish for another person to get married soon), a comedy-drama movie directed by Yassine Fennane and released in 2010. The second one is Hayat (meaning life in Arabic), directed by Raouf Sebbahi and released in 2017.

\section{METHOD}

This paper explores the extent to which women are underrepresented by Moroccan male filmmakers in Moroccan drama movies. To achieve this objective, two Moroccan drama movies are selected mainly due to their popularity and controversy: Okba Lik directed by Yassine Fennane and Hayat directed by Raouf Sebbahi. To objectively analyze the intentions of both male filmmakers, understand the way gender is represented, and identify bias and gender discrimination, this paper utilizes qualitative content analysis which is applied to systematically study and analyze both the implicit and explicit meanings of the communicated content of both movies.

\section{ANALYSIS AND DISCUSSION}

\section{Analysis of Okba Lik}

Okba Lik is a comedy-drama film that attempts to realistically address some social and cultural issues. It narrates the story of a Moroccan lady who finds herself in conflict with her surroundings and her society that appears to be judgmental. The main character, Fatima Ezzahra, has achieved professional success and satisfaction and has sought a free and independent life. However, she has always suffered from the pressure to get married.

From the perspective of her environment, the definition of a successful woman is strictly tied with building a family at an early age. However, her definition of success is to attain wealth, self-satisfaction, and professional growth. Still, the male filmmaker chose to reinforce and perpetuate the traditional patriarchal ideology that forces women, regardless of their academic background and social status, to believe and accept that their ultimate goal in life should be finding a man, getting married, and having children.

The main character has two close friends who hold completely different mindsets. One of them, Lamiae, is married, pregnant, and has two other children. Her husband publicly cheats on her but only her close friends know. Still, they choose to remain silent. This woman represents a particular category of Moroccan women who hold an internalized patriarchal mindset due to different internal and external factors. Throughout the movie, Lamiae's role is to glorify her husband and idolize marriage. She constantly reminds Fatima Ezzahra that she reaches the age where she should build a family of her own. She strives to reinforce and circulate her viewpoints and beliefs and emotionally convince Fatima Ezzahra that women's happiness lies in their private sphere with both their husbands and children. On the contrary, her other friend, Sofia, is a rebellious woman who does not abide by societal pressure that is practiced on women. Instead of stressing Fatima Ezzahra out, Sofia tries to normalize the feeling of being fulfilled without getting married.

However, the male filmmaker chooses to make Fatima Ezzahra believes that she as well needs a man to be fully fulfilled. He chooses the main character as a woman whose successful professional life is not sufficient to build a happy life. Instead, through this narrative, the film director attempts to promote the patriarchal ideology that necessitates and prioritizes the existence of a man in a woman's life, indoctrinating hyper-masculinity and limiting women's choices and success. 


\title{
International Journal of Current Science Research and Review
}

\author{
ISSN: 2581-8341
}

\section{Volume 04 Issue 01 January 2021}

DOI: 10.47191/ijcsrr/V4-i1-07, Impact Factor: 6.825

IJCSRR@ 2021

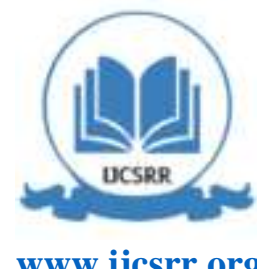

The first scene commences with a traditional Moroccan wedding where three female invitees are attempting to convince the main character that she needs to get married at the earliest possible time, as she is in her 30s. This scene symbolizes the common traditional mindset that many Moroccan traditional families hold. This mindset seeks to psychologically manipulate women's mind to accept that getting married is the greatest accomplishment they could ever achieve. Soon later, the main character starts questioning her situation. She begins seeing herself through the lens of her surroundings, problematizing her age along with her life decisions. This has led her to adopt the dominant perception of life that makes marriage her first priority. Since then, Fatima Ezzahra's life has undergone a radical change: from being a successfully self-supporting woman into a woman whose whole life revolves around finding a potential husband.

Her male friend has introduced her to a dating website where she could select anyone she wants and arrange a date with him. She immediately liked Adil, a 33-year-old architect, and went to a date with him. The scene of their first date reveals men's control and dominance over women. This unequal distribution of power and dominance in male-female relationships is clearly demonstrated in the way Adil initiates the conversation, asks questions, maintains eye contact, makes decisions, and changes Fatima Ezzahra's preferences. Usually, Fatima Ezzahra drinks her coffee with 3 teaspoons of sugar. However, Adil told her to better drink it with one piece of sugar and she instantly and happily accepted. Meanwhile, when Fatima Ezzahra wanted to add sugar to his coffee, he stopped her, claiming that he likes drinking it without sugar. The second date is a real manifestation of the male gaze. It is where the male filmmaker employed the zoom effect on Fatima Ezzahra's lips and eyes. This scene represents the way the male filmmaker aims at satisfying the Moroccan male's visual pleasure through Fatima Ezzahra's body parts. After three more dates, Adil left her and she then found out that he is married and has a son. Fatima Ezzahra has experienced difficult times of depression and grief. Nevertheless, she starts once again her journey of finding the right man so she could regain her confidence and self-esteem and feel fully fulfilled, satisfied, and content. The end of the movie reflects the main character's consent to the position of the three female invitees with whom the film started. Fatima Ezzahra has eventually succeeded in finding her ideal man with whom she felt complete.

The movie employs a diverse number of images that both mold and mirror Moroccan culture. The film reflects society's concerns and expectations of women when it comes to marriage. It shows the extent to which marriage is a social and cultural issue that Moroccan women are brainwashed about, forced into, and blamed for. However, instead of challenging traditional mindsets and debunking gender stereotypes that always make women seem helpless, dependent, and unfit without the presence of men, the male filmmaker portrays women from an objectified, sexualized, and misrepresented perspective.

\section{Analysis of Hayat}

Hayat is a road trip drama movie that dramatizes the relationship between the Moroccan individual, the other, and their society. It also addresses some of the most contemporary social problems: poverty, immigration, prostitution, and social stratification. However, the film director tackles these issues by integrating a diverse number of gendered images and distorted representations of Moroccan women. Accordingly, this particular movie has been strongly criticized, as it promotes a misleading impression of Moroccan culture, it exaggerates events, and it produces a misrepresented image of Moroccan women.

The first scene begins with the first theme of the film: diversity. The male filmmaker starts by picturing different Moroccan immigrants whose facial expressions, clothes, and manner of speech expose their different beliefs, values, and principles. From the port to the bus until their destination, the passengers have developed new relationships, have argued with each other, have deepened their understanding of themselves and others, and have exposed their inner thoughts and beliefs to the audience.

The focus of the male filmmaker is mainly on revealing the differences and similarities in the perception of the opposite sex. The choice of passengers, the methods of building dialogue, and the way female passengers and male passengers gaze at each other reflect the filmmaker's sense of right and wrong and his ideological perspectives of gender and cultural norms in general. The first woman who sits in the front of the bus aims at building a sexual relationship with the bus driver so that she and her friend will pay no transportation fees. Accordingly, she starts performing sexual advances to attract and seduce the bus driver. He in turn starts looking at her from a sexualized and objectified point of view.

The second woman is pregnant, wears Khimar, and is married to a religious extremist person who looks at her as if she is his property. The woman herself seems fearful, helpless, subordinate, and entirely dependent on him. In one of the stop stations, this couple and almost all the passengers get off the bus and get distracted. A group of musicians attracts the attention of the pregnant woman who immediately responds to the music rhythm and starts dancing, taking off her Hijab. Once her husband notices this scene, he starts violently attacking her, both verbally and physically. Through this character, the filmmaker attempts to reveal the extent to which women with Khimar are oppressed, abused, and mistreated. He aims at tackling the relationship between religion, 


\section{International Journal of Current Science Research and Review}

ISSN: 2581-8341

Volume 04 Issue 01 January 2021

DOI: 10.47191/ijcsrr/V4-i1-07, Impact Factor: 6.825

IJCSRR@ 2021

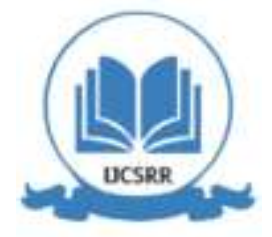

www.ijcsrr.org

religious dress, women, and men's dominance. Filming this scene unveils the filmmaker's perception of veiled women, affirming that wearing Hijab/Khimar is not done by choice but rather women are forced to wear it.

The third woman, Fairouz, acts as a woman who seeks the acceptance of a man to feel a sense of self-esteem, self-acceptance, and self-satisfaction. Throughout the road, Fairouz's ultimate aim is to feel loved, appreciated, accepted, and desired by a man whom she just meets. She keeps sexually harassing him, over-glorifying him, and showing him her intense feelings, but in vain. Through this character, the male filmmaker portrays women as a human being who could do anything to get emotional attention from the opposite sex. This character is depicted as helpless, dependent, and always in need of a man to feel fully fulfilled.

The fourth woman is Nadia, a young lady who immigrated to France to obtain her higher degree. However, she gets easily distracted and influenced by the prostitute lifestyle of her friend that circles around self-dehumanization and money prioritization. Nadia is a character made by the male filmmaker to demonstrate that women who are willing to travel abroad for academic purposes should be unencouraged to do so, as they are target to violence, sexual exploitation, and safety issues. Therefore, the male filmmaker promotes the patriarchal mindset that assigns people to different roles based on their sex and gender. This mindset looks at women as incapable to independently live abroad without any kind of help, support, and protection from the part of men.

Another important point that should be highlighted is the dialogue of the two old adult men that can be described by being discriminatory, aggressive, and humiliating. One of these men is involved in polygamous marriages and wants to marry a younger woman that would better satisfy his desires. He expresses that he has no interest in his wives as they got older and their attention is entirely on their children. He explains to his friend that the young woman with whom he has a relationship is divorced which will facilitate the whole marriage process, as she desperately needs a man to socially, emotionally, financially, and physically protect her, regardless of his age. This dialogue conveys social discrimination against women and particularly divorced women. It tends to promote that divorced women can be easily attracted, seduced, and manipulated.

In the final analysis, both Okba Lik and Hayat represent women from a masculine perspective. The two drama movies have not invested effort in challenging the traditional mindset that believes in men supremacy and women subservience. Okba Lik portrays gender from a stereotypical perspective. It attempts at challenging the traditional mindset of some Moroccan people but ends up promoting the same mindset. Although the main character's major focus was mainly on freeing herself from societal pressure, she ends up conforming to gender norms and expectations. Similarly, Hayat presents a misrepresented image of Moroccan women. The film director provides limited, biased, and stereotypical representations of Moroccan women that negatively portray them: from being materialistic to fully dependent on men, to sexually driven. The way female characters are filmed, dressed, and addressed reflect the kind of ideological patterns Moroccan male film directors tend to convey and disseminate. The hegemonic representation of patriarchal culture is clearly observed in the way the directors depict men abusing women, oppressing them, cheating on them, and devaluing their achievements. Therefore, the way both movies profile and categorize female characters shows the extent to which Moroccan male directors perceive women as being dehumanized, subordinate, and sexually objectified.

Consequently, although the Moroccan film industry has made remarkable progress in the use of cinematography techniques along with the movie script formatting, empirical evidence indicates that the portrayal of women still reflects traditional gender profiling.

\section{CONCLUSION}

This study unveils that the culture of domineering men and subservient women is still prevalent in Moroccan drama movies. Although women in the two movies dominate the scenes and appear more often than men, the male filmmaker has continued to misrepresent, dehumanize, objectify, and sexualize women.

As the audience continues to view images that promote gender stereotypes and women objectification, most of them will interpret such media texts as being normal, acceptable, and reasonable. Hence, their actions along with their thoughts will get automatically influenced by what their brains are exposed to the most.

Okba Lik has given three main images of women: Lamiae who occupies the traditionally female occupation and who is fully dependent on her husband, Sofia who rejects being objectified by her surroundings, and Fatima Ezzahra who is academically qualified, professionally successful, and financially stable but still feeling unsatisfied and unhappy for being single. Instead of choosing a major character who challenges traditional mindsets that underrepresent women and limit their progress, the male filmmaker chooses Fatima Ezzahra as the main character whose main aim was to debunk gender stereotypes but ends up conforming 


\section{International Journal of Current Science Research and Review}

ISSN: 2581-8341

Volume 04 Issue 01 January 2021

DOI: 10.47191/ijcsrr/V4-i1-07, Impact Factor: 6.825

IJCSRR@ 2021

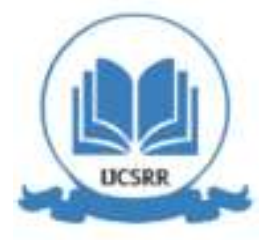

www.ijcsrr.org

to societal expectations. Through this narrative, the male filmmaker promotes gender stereotypes, more specifically, picturing marriage as women's top priority, regardless of their academic and professional achievements.

In Hayat, women were more portrayed as oppressed, subordinates to men, and sexual objects whose main aim is to attract and gratify men's visual and sexual pleasure. Most female characters are represented from a sexualized point of view, either looking for sexual and emotional attention from the opposite sex or using their bodies for financial purposes. Other female characters are placed in a subordinate position where men are portrayed as oppressors and women as the oppressed.

Through the analysis of both movies, it has been manifested that throughout seven years, the Moroccan male filmmaker still holds the same insight about gender. He unevenly distributes power, roles, and dominance. By illustrating stereotypical gender images, the Moroccan male filmmaker contributes to a large extent to the perpetuation of patriarchal ideologies that are based on a superordinate-subordinate hierarchy where males are privileged and females are subjugated.

\section{ACKNOWLEDGEMENT}

This research is financially supported by CNRST, the National Center for Scientific and Technical Research of Morocco.

\section{REFERENCES}

1. Talbot, M. (2007). Media Discourse: Representation and Interaction. Edinburgh: Edinburgh University Press. Retrieved September 9, 2020, from http://www.jstor.org/stable/10.3366/j.ctt1r2cp1.

2. Hall, S. (1997). Representation: Cultural Representations and Signifying Practices. The Open University.

3. Hagey, R., \& MacKay, R. (1994). The Politics of Representation in Racism and Gender. Medical Anthropology Quarterly, 8(1), new series, 106-109. Retrieved September 7, 2020, from http://www.jstor.org/stable/648998.

4. Gorton, K. (2009). Media Audiences: Television, Meaning and Emotion. Edinburgh: Edinburgh University Press. Retrieved September 2, 2020, from http://www.jstor.org/stable/10.3366/j.ctt1r26bz.

5. Gerbner, G. (2013). Television: The New State Religion? ETC: A Review of General Semantics, 70(4), $462-467$. Retrieved September 5, 2020, from http://www.jstor.org/stable/24761814.

6. Tuchman, G., Daniels, A. K., Kaplan, D., \& Benét, J. W. (1978). Hearth and Home: Images of Women in the Mass Media. Oxford University.

7. Shrum, L., Burroughs, J., \& Rindfleisch, A. (2005). Television's Cultivation of Material Values. Journal of Consumer Research, 32(3), 473-479. doi:10.1086/497559.

8. Mulvey, L. (1975). Visual Pleasure and Narrative Cinema. Screen, 16(3), 6-18. https://doi.org/10.1093/screen/16.3.6.

9. Manlove, C. (2007). Visual "Drive" and Cinematic Narrative: Reading Gaze Theory in Lacan, Hitchcock, and Mulvey. Cinema Journal, 46(3), 83-108. Retrieved September 10, 2020, from http://www.jstor.org/stable/30130530.

Cite this Article: Sarra Chahbane (2021). The Underrepresentation of Women in Moroccan Drama Movies: Through the Lens of Moroccan Male Filmmakers. International Journal of Current Science Research and Review, 4(01), 40-44 